\title{
RECONFIGURING THE URBAN LANDSCAPE OF LA PLATA THROUGH A GREEN NETWORK
}

\author{
Jensen Karina, Birche Mariana \\ National University of La Plata - CONICET (ARGENTINA) \\ karinacjensen[at] gmail.com, marianabirche[at]gmail.com
}

\begin{abstract}
This investigation aims to incorporate new visions and tools that investigate the public green space as a fundamental element that structures urban life and shape our cities. In this sense, the city of La Plata presents an imbalance between its planned foundational quarter and the periphery. This is reflected by the periferic landscape that loses the main characteristics of the urban landscape of La Plata, fundamentally recognized by its avenues and green spaces every six blocks. This article proposes guidelines and criteria to reconfigure the landscape through a green network in order to improve the quality of the urban environment.
\end{abstract}

Keywords: Urban planning, landscape, green network

\section{INTRODUCTION} \section{Public space and landscape as key elements in the city structure}

From very early the landscape was associated with urban interventions, such as the Central Park, designed in 1858 by Frederick Law Olmsted and Calvert Vaux. They continue with a series of interventions called parkways that proposed the incorporation of green avenues to way of ecological corridors to conform urban systems of green spaces or park systems, such is the case of the design also by Olmsted for the city of Boston in 1894. In this sense, it can be affirmed that the landscape historically thinks the city and not only the design of the park or the plaza. The public park appears as an institution that represents the spirit of the new society and at the same time shapes the city.

In different countries, between 1890 and 1920, the social question and the housing question are far from the scope of the sectoral measures promoted by the newly born social housing policies and in this way the question begins to be formulated as "urban". It is here when urban planning is formally constituted as a discipline, along with the profession of urban planner. At the same time, a process of extreme scientific-technical reductionism takes hold, conceiving that thinking was the only thing that separated man from nature. This situation turned into a gradual transformation of the idea of landscape (aesthetic perspective) into the idea of environment (scientific perspective), which slowly displaces the notion of landscape outside of urbanism, neglecting issues of social demand and considering it a purely aesthetic issue or superficial.

Subsequently, criticisms of sustained growth and the deterioration of the environment and natural resources reached an international momentum due to the report "Limits to Growth". This report is commissioned by the club of Rome to specialists from MIT, which was published in 1972. In this report, it warned about the limits of the natural environment and the reserves of non-renewable resources 


\section{\#3/2018 URBAN CHALLENGES}

as opposed to exponential economic growth. In this context, and after the first oil crisis in 1973, the landscape reappears with new interest from the idea of nature and the need to preserve it, complementing the new vision provided by ecology. However, during the 1980s the landscape concept gradually merges with a strong environmental imprint that continues to this day.

From here, the word landscape was frequently used as a synonym of nature, when "For a landscape to exist it is not enough for nature to exist, it is necessary a point of view and an observer, a story that gives meaning to what is looked at"[1]. In this way, the landscape is nourished and shaped according to the guidelines imposed by nature and the place in which it is inserted, the society that constructs it, the subject that perceives it and the artist that designs it.

The theoretical questions about landscape are shared by several disciplines. Most authors who work with the landscape concept point out the ambiguity of the term, which designates it as a set of real objects, a portion of territory, and also its image and graphic representation (Silvestri, 2001; Roger, 2007; Santos, 2000).

In this regard, Agustín Berque points out that landscape refers both to the physical nature and the phenomenal nature of it. "The environment is not a physical object, it is an existential relationship, it is the relationship of society with this" [2]. This situation, far from being a disadvantage, in which it can be more powerful and with the lower probability of becoming reality and in the representation of a territory proper to postmodernity, in the quality between real and its representation becomes blurred [3].

For the development of this work, we begin to understand the differences and spatial gaps in the landscape as sociological facts that contain and give meaning to spatial forms and not spatial facts that produce sociological effects. The notion of landscape is then a key factor in addressing the relationship between society and nature. In this way, it is necessary to begin this reflection by pointing out the definition adopted by the European Landscape Convention (2000):

"Any part of the territory as perceived by the population, whose character results from the action of natural and human factors and their interrelations".

In Argentina, the landscape does not exist as a very worked discipline. Nor is there a definition of landscape in terms of the legal system and its appearances in regulations or legislation, it is usually ambiguous. Although in some cases the notion of landscape has been incorporated into some urban projects, these examples are very limited and, in general, of a limited conceptual approach.

If the periphery's situation is specifically considered, understood as an urban area of recent consolidation and expansion, it can be hold that this has housed the city growth process and responded to the urban transformations that the urban center has not been able to resolve. The deep connection between the peripheral developments such as malls and closed urbanizations and the growth of the city, allows us to think of the periphery as a daily support of the life of man and it triggers the need to study their pathologies and landscape deficiencies. These problems, arising in parallel to the peripheral urban growth, have evidenced the need to include their inhabitants in the city and at the same time they have begun to manifest occupying residual spaces currently functioning as informal public green spaces.

Public spaces are one of the elements for the emotional patrimonialization of the city. It is understood here by affective patrimonialization the ability to generate stable affective bonds of identification and attachment with the city. Without these public spaces, the city loses the capacity to generate a symbolic and 


\section{\#3/2018 URBAN CHALLENGES}

significant pattern of activity that favors the involvement of citizens in the urban space and with the rest of the inhabitants who occupy it. And a large part of the risks that make urban spaces vulnerable derive from the scarcity and / or low quality of these.[4]

In this way, the interest of the investigation arises then from the observation of a reality based on the need not only academic but also the social environment to incorporate new views and tools that investigate the public green space as a fundamental element that structures urban life and shapes our cities.

Therefore, green infrastructure is understood as an interconnected network of public green spaces (linear parks, squares, parks and greenways) that preserves and provides ecosystem functions and environmental services for the human population, water treatment, improvement of air quality, mitigation of heat island effects, biodiversity and wildlife, recreation, scenic beauty and protection from disasters, among other benefits.

\section{METHODOLOGY}

The proposed methodology starts from considering the landscape as the result of the action between man and nature, which is expressed in the image of the processes that take place in the territory, either corresponding to the natural or human scope applying logical and empirical methods. The former in order to deduce, analyze and synthesize the existing knowledge, while the latter approach the knowledge of the object through empirical observation.

In the first instance, we proceeded to the survey of the urban area of La Plata, identifying the existing green spaces. In a second instance, the road network is analyzed. And finally, a guidelines serie was set with the aim for integrating the existing greenways and green spaces with the greenways and green spaces proposed in a reconfigured green network.

In the foundational quarter of the city live 191,075 inhabitants while in the periphery live 392,821 inhabitants, where the urban area has $4,607,812.9 \mathrm{~m}^{2}$ of green areas of the $8,850,960 \mathrm{~m}^{2}$ that exist throughout the city. These numbers show the differences between the foundational quarter and the periphery. It is proposed to adopt four analysis zones, respecting the three zones proposed by the Public Space Code of La Plata (2004) in its art. 10 [5], but subdividing the third zone comprising the Northwest Axis and the rural locations of the Green Belt, understanding they respond to different realities and conformation processes. In this way, the following zones are adopted:

- Foundational quarter, delimited by Circunvalación Avenue according to the design established since its foundation.

- Foundational Quarter Adjacency, generated from the first growth processes outside Circunvalación Avenue. It is conformed by the delegations adjacent to the Foundational Quarter: Tolosa, San Carlos, Los Hornos, Altos de San Lorenzo and Villa Elvira.

- Northwest Axis, understood from the growth around the main connectivity routes of the city with the city of Buenos Aires. It includes the towns of Villa Elisa, City Bell, Gonnet, Ringuelet, Gorina and Hernández.

- Green belt is made up of the Urban Reserve of the Complementary Area and the sector of the Intensive Rural Zone. It is conformed by the locations of Arturo Seguí, Melchor Romero, El Peligro, Abasto, Etcheverry and L. Olmos.

Regarding green spaces, Decree-Law 8912/77[6] on Territorial Planning and Land Uses, establishes in Art. 8 that public green and free spaces are those in which 


\section{\#3/2018 URBAN CHALLENGES}

vegetation and landscape predominate and whose main function is to serve the recreation of the community and contribute to the purification of the environment, adding in its Art. 13 that there must be a minimum of $10 \mathrm{~m}^{2}$ of these spaces per inhabitant, following the minimum of the World Health Organization. However, it should be noted that in this work, spaces for public use are considered as a different concept within what in the general bibliography and in the Argentine legal system is called as public space. While the public space itself refers to that which is state ownership, the space for public use or collective space refers to those places encompassed in the urbanized territory that, as Cerasi (1990) [7] states, have an impact on collective life, define a common use for broad strata of the population and that constitute the seat and the places of their collective experience. That is to say, that collective spaces or spaces for public use do not necessarily have to be registered in the state ownership, but rather be spaces that constitute new areas of social appropriation. This situation makes suspect a change in the concept, image and valuation of public space, which this work proposes to address. In this way, it is proposed to study those spaces based on the definition of Law 8912/77 but also allow the inclusion of green spaces for public use of private ownership and comply with the following premises:

1. To have as a function and destiny the recreation or the practice of sports or games by the inhabitants, as well as the enjoyment of aesthetic qualities of the place.

2. Possess a structure where the fundamental and characteristic element is generally vegetation. These spaces are bearers of distinctive elements at the level of the surrounding landscape, as well as the possibility of offering from the space itself, general views of the environment.

3. Free and free access, that is, there are no restrictions or access costs.

Based on the premises previously described for the survey, three dimensions are established which are composed of their respective variables: the urban dimension, which aims to study the relationship between the PUGS and the urban environment, the social dimension, which aims to understand the reach zone of every space type and the landscape dimension that seeks to rescue the aesthetic valences of the place. In this way, it is proposed:

Urban dimension: in this dimension three variables were taken to analyze. a) The type, which is in relation to the shape and size. b) The ownership, which responds to whether it is state or private ownership and finally c) absorbent ground cover percentage that has the PUGS in relation to its whole area.

Social dimension: in this dimension two variables of analysis were taken. a) The reach zone is related to the area of influence or attraction level depending on every space type, and b) the furniture refers to whether it has the necessary furniture in correspondence to the space type.

Landscape dimension: This dimension takes as analysis variables the quantity of trees and also takes the presence of surface water, as a key variable respect to the landscape quality of a site.

Consequently, for each of the proposed analysis variables, the following indicators were developed in order to establish values that will allow the PUGS to be cataloged: 


\begin{tabular}{|c|c|c|c|}
\hline DIMENSION & VARIABLE & INDICATOR & VALUE \\
\hline \multirow{10}{*}{ URBAN } & \multirow{4}{*}{ TYPE } & $\begin{array}{l}\text { Dimension: greater than or equal to } 40,000 \mathrm{~m} 2 \text { - } \\
\text { Form: width / length ratio equal or very close to one. }\end{array}$ & PARK \\
\hline & & $\begin{array}{c}\text { Dimension: greater or equal to } 10,000 \mathrm{~m} 2 \text { and less } \\
\text { than } 40,000 \mathrm{~m} 2 \text { - Form: width / length ratio equal or } \\
\text { very close to one. }\end{array}$ & SQUARE \\
\hline & & $\begin{array}{l}\text { Dimension: between } 10,000 \mathrm{~m} 2 \text { and } 5,000 \mathrm{~m} 2 \text { - } \\
\text { Form: width / length ratio equal or very close to one. }\end{array}$ & $\begin{array}{l}\text { PEDESTRIAN } \\
\text { PLAZAS }\end{array}$ \\
\hline & & Shape: length predominates over the width & CORRIDOR \\
\hline & \multirow{2}{*}{ DOMAIN } & Ownership publishes & PUBLIC \\
\hline & & private ownership & PRIVATE \\
\hline & \multirow{4}{*}{$\begin{array}{l}\text { ABSORBENT GROUND COVER } \\
\text { PERCENTAGE }\end{array}$} & \multirow{4}{*}{$\begin{array}{c}\text { Absorbent ground proportion in relation to the total } \\
\text { area of a public green space }\end{array}$} & $75 \%$ to $100 \%$ \\
\hline & & & $50 \%$ to $75 \%$ \\
\hline & & & $25 \%$ to $50 \%$ \\
\hline & & & 0 to $25 \%$ \\
\hline \multirow{6}{*}{ SOCIAL } & \multirow{3}{*}{ RANGE } & $\begin{array}{l}\text { Attractor that exceeds the scale of a city but does not } \\
\text { exceed the scale of urban agglomeration }\end{array}$ & REGIONAL \\
\hline & & $\begin{array}{l}\text { Attractor that exceeds the scale of a city but does not } \\
\text { exceed the scale of the region }\end{array}$ & URBAN \\
\hline & & Local attractor & LOCAL \\
\hline & \multirow{3}{*}{ FURNITURE } & Contains additional furniture to the default for type & SUPERIOR \\
\hline & & $\begin{array}{c}\text { Space that contains the default furniture Park: } \\
\text { luminary, benches, baskets. } \\
\text { Plaza: luminary, benches, baskets, games for } \\
\text { children. } \\
\text { Square: luminaire, benches, baskets. } \\
\text { Corridor: luminary, baskets. }\end{array}$ & BASIC \\
\hline & & It has less than the default basic & DO NOT HAVE \\
\hline \multirow{6}{*}{ LANDSCAPE } & \multirow{4}{*}{ TREES } & \multirow{4}{*}{ Forestation proportion in relation to the total area } & $75 \%$ to $100 \%$ \\
\hline & & & $50 \%$ to $75 \%$ \\
\hline & & & $25 \%$ to $50 \%$ \\
\hline & & & 0 to $25 \%$ \\
\hline & \multirow{2}{*}{ PRESENCE OF SURFACE WATER } & \multirow{2}{*}{ Existence of a surface water } & YES \\
\hline & & & NO \\
\hline
\end{tabular}

TABLE 1: Table for relevance of green spaces. Source: Own elaboration, 2016

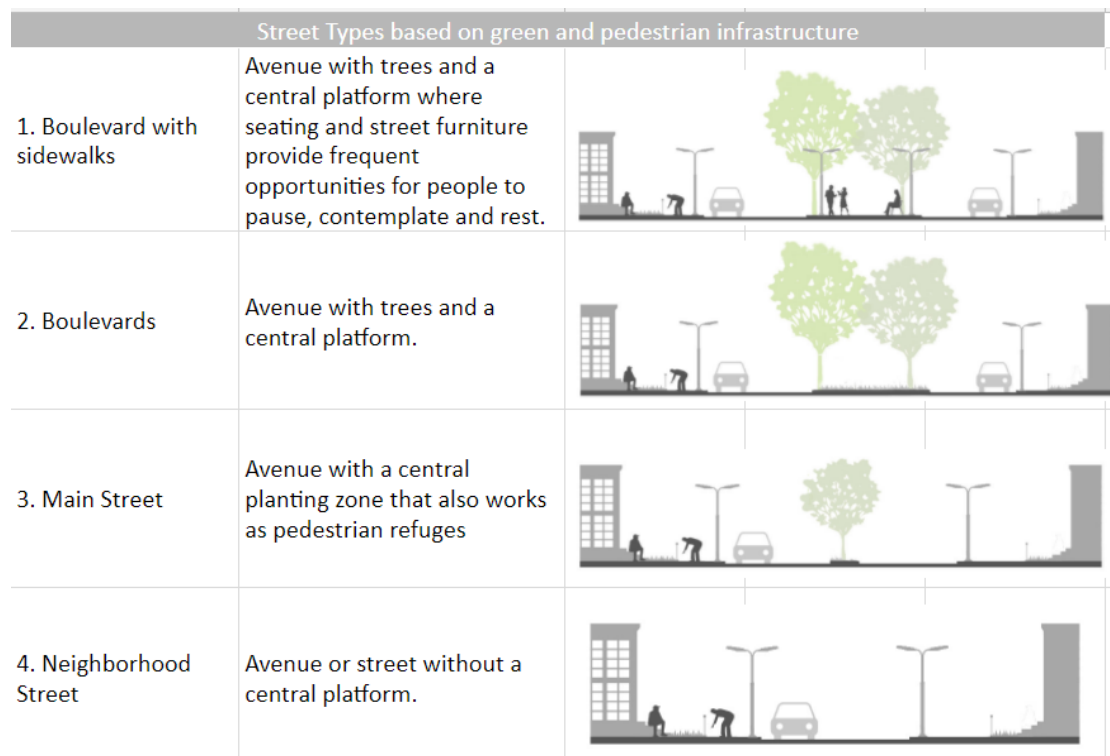

TABLE 2: Street Types. Source: Own elaboration, 2016 


\section{\#3/2018 URBAN CHALLENGES}

On the other hand, the roads were surveyed based on four types established by the predominant morphologies in the city streets, prioritizing the presence of trees, and the infrastructure available for pedestrians.

\section{RESULTS}

As a result of the survey work carried out, it was obtained systematized cartographies in GIS as a diagnosis mapping.

A GIS map is proposed since it has been "applied in a wide variety of situations, including ecological approaches to define the aptitude inhabitant of the land for animal and plant species, geological favorability, suitability of land for agricultural activities, landscape evaluation and planning, environmental impact evaluation, selecting the best site for public and private sector facilities and regional planning "[8].

In the cartographies obtained, it is observed in the foundational quarter a green network formed by the green spaces and the main roads. In the three periferic analizis zones, this system disappears completely, evidencing a marked contrast between the planned city and the rest of it.

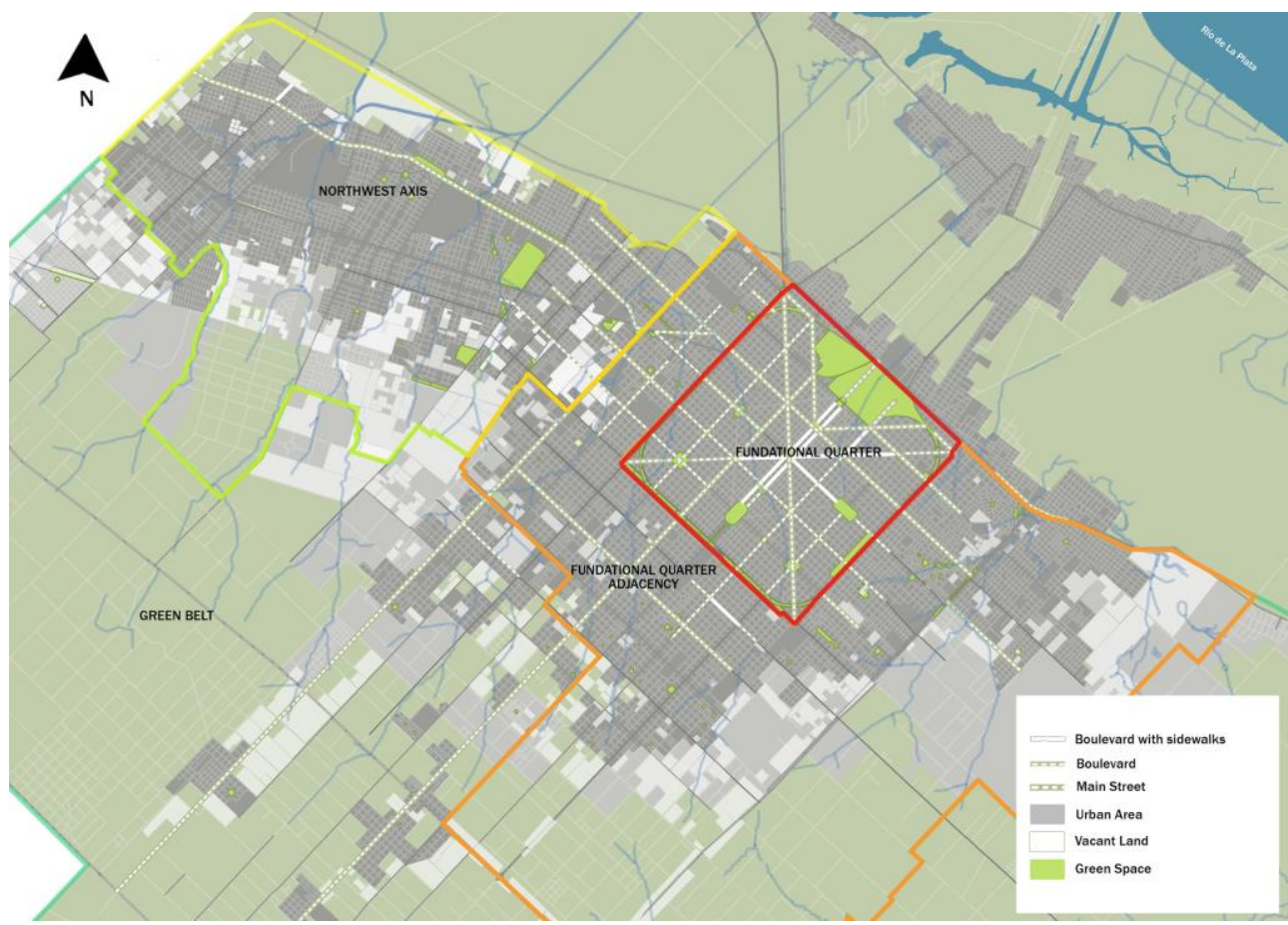

Figure 1: Current situation. Source: Own elaboration, 2016.

In this way, it was also possible to elaborate guidelines to carry out a series of modifications to the system of green spaces in the city in order to constitute a green network that allows to reconfigure the peripheric landscape:

1. Improve the quality of the green spaces and the street system existing, adding vegetation and pedestrian infrastructure as urban furniture where needed, according to the diagnosis. 


\section{\#3/2018 URBAN CHALLENGES}

2. Select a series of vacant lands and propose them as green spaces in the periphery, following the guidelines of the foundational grid, understanded as a characteristic landscape of La Plata. This way, the vacant lands are selected by their proximity to the different roads intersections and seek to shape a similar system to the six block grid in the foundational quarter.

3. Select streets categorized as Boulevard and propose them as Boulevard with sidewalks, improving the opportunities for walking and cycling.

4. Select streets categorized as Main Street and incorporate vegetation to shape them as greenways and biological corridors, increasing shadow areas for pedestrians and contributing to mitigate the heat island effect.

This guidelines seek to promote the recovery, rehabilitation or re-functionalization of residential urban sectors in the process of degradation, through key urban elements such as vacant lands, understanding that "Landscapes and urban green space plays a critical role for keeping our cities attractive and healthy" [9]. Therefore, the following plan is proposed:

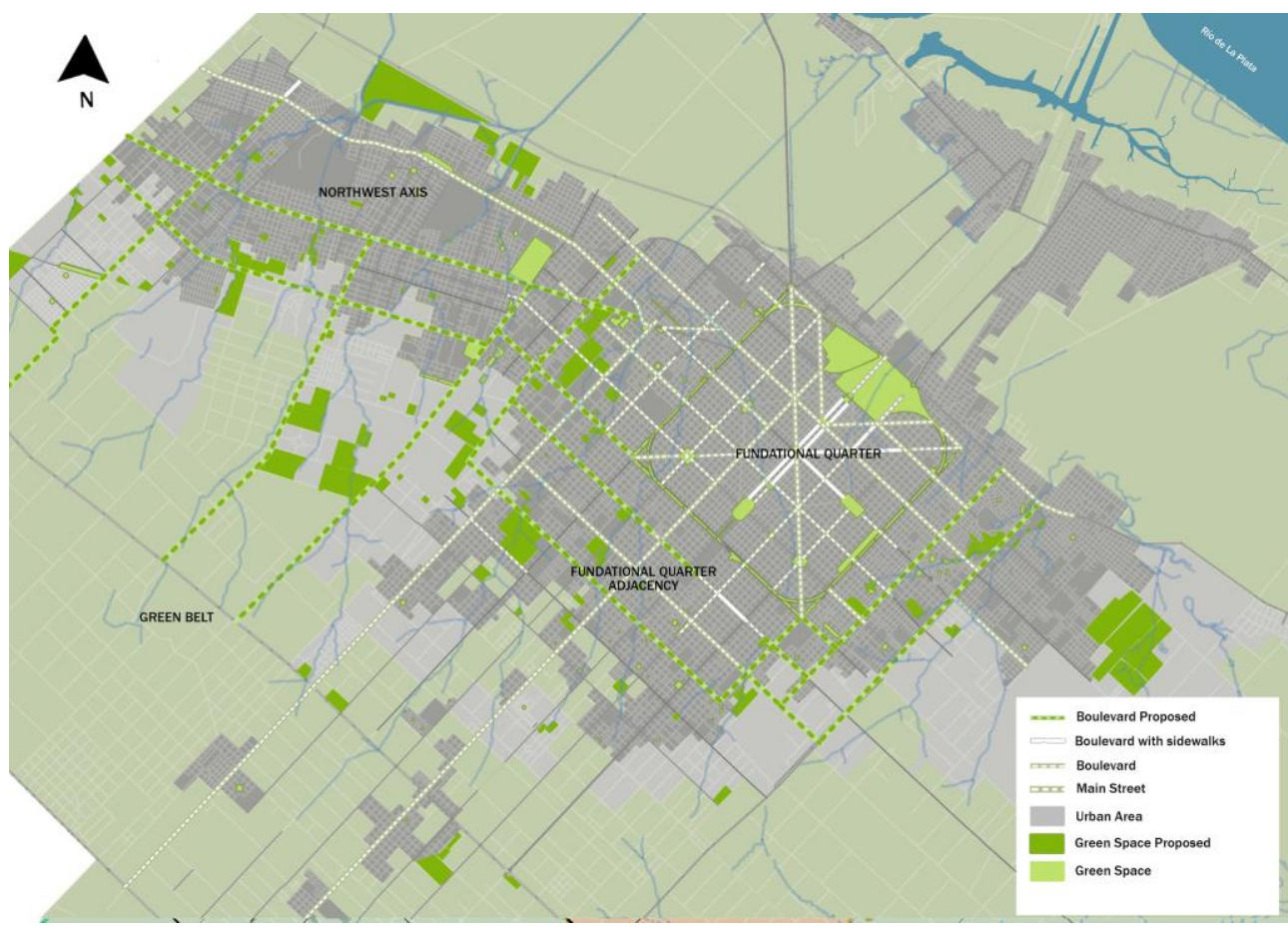

Figure 2: Proposed situation with new roads and green areas. Source: Own elaboration, 2016.

In this way, the proposed system could incorporate 12.348 .000 square meters of green space and 83.903 linear meters of green ways, improving the spatial distribution of public green space (as shown in Figure 2) to promote social accessibility.

\section{CONCLUSIONS}

Understanding the territory through the landscape implies the articulation of the cultural and natural aspects, assuming the continuous interaction between both. 
The reconfiguration of the landscape through the implementation of a green network should aim to stop the loss of identity and landscape quality of the urban territory by providing similar conditions in the periphery as in the city center.

Besides, the guidelines proposed from the survey carried out will allow to create a public green network and encourage pedestrian and cycling mobility.

Working the landscape of the periphery through a green network would improve the quality of the urban environment, tending to form a more equitable city for the society in general. This green network could take advantage of the benefits the vegetation provides like the $\mathrm{CO}^{2}$ absorption, provide new shadow areas, create safer walking environments, convert streets and green spaces into more aesthetically pleasing environments and even reduce blood pressure, improving overall emotional and psychological health.

\section{REFERENCES}

[1] Aliata, F y Silvestri G. (2011), El paisaje como cifra de armonía, Nueva Visión, Buenos Aires.

[2] Berque, A. (1996), Être humains sur la terre. Principes d'éthique de l'écoumène, Paris, Gallimard, $212 \mathrm{pp}$.

[3] Souto, P. (2011), Paisajes en la geografía contemporánea: concepciones y potencialidades. Revista Geográfica de América Central, 1-23.

[4] Corraliza, J. A. (2009), Emoción y espacios públicos: La experiencia humana de los escenarios urbanos, Universidad Autónoma de Madrid, Madrid.

[5] Public Space Code. Deliberative Council, Municipality of La Plata. [online] Buenos Aires, Argentina, 2004. [Accessed 13 December 2017] Available at: http://www.concejodeliberante.laplata.gov.ar/digesto/cod_espacio/or9880_indice.a $\mathrm{sp}$

[6] Decree-Law 8912. Law of Territorial Regulation and Land Use of the Province of Buenos Aires. [online] Buenos Aires, Argentina, 1977. [Accessed October 20, 2017] Available at: http://www.gob.gba.gov.ar/legislacion/legislacion/l-8912.html

[7] Cerasi, M. (1900), El espacio colectivo de la ciudad.

[8] Ryngnga, Pk., GIS- Based Land use Suitability Analysis for Urban Development, THE GLOBAL JOURNALS.

[9] Roy, R. K., Khuraijam, J. S. \& Singh, S. (2015), Landscaping Lagerstroemia for Urban Landscapes in India, IJSR - INTERNATIONAL JOURNAL OF SCIENTIFIC RESEARCH, Volume: 4, Issue: 6.

\section{Article distributed under a Creative Commons Attribution- NonCommercial-NoDerivatives 4.0 International License (CC BY-NC-ND).}

Received: April 16, 2018

Accepted: May 23, 2018. 